\title{
Histological Study on the Healing of Rat Dental Sockets after Partial Removal of the Buccal Bony Plate
}

\author{
by \\ Tetuo OKAMOTO* and Ayrton ONOFRE DA SILVA**
}

\begin{abstract}
A comparative study was conducted on the healing process of the dental socket after simple extraction or extraction after bony plate removal. The last procedure was associated with more intense inflammatory reactions, delayed healing, and morphological alterations of the alveolar crest.
\end{abstract}

Key words: dental socket—wound healing-alveolectomy.

\section{Introduction}

Several local factors may influence the healing process of extraction wounds, such as permanence of the alveolar crest[4] or fractured septum within the alveolar socket. Curettage and irrigation may also disturb healing[2].

Sometimes, the elected extraction technique itself may interfere with the chronology of the healing process; use of rotatory instruments, chisels or even extractors may elicit a more pronounced inflammatory reaction.

SIMPSON[11,12] studied the healing process of extraction wounds in monkeys by comparing the different osteotomy techniques of chisels and burs and concluded that the use of chisels is less harmful to healing because bone fragments are more easily removed than those found after the use of burs.

In teeth that have extremely curved roots, cement hyperplasia or the presence of remaining roots, extraction by alveolectomy is indicated, that is, the tooth is extracted after the partial or total removal of the buccal bony plate.

According to SCHUCHARDT[10], tooth extraction by alveolectomy is indicated when the tooth cannot be removed through a routine procedure, i.e., when roots are very deeply seated, when surgery must be performed in a short time and when less lateration of the tissue is imperious.

ScHRAN[9] reported that the removal of the buccal alveolar wall creates a small area to be filled up by bone, thus promoting faster healing.

However, surgical trauma may elicit a more intense and prolonged inflammatory reaction which may affect the chronology of the healing process. Thus, the present study was carried out, in which the influence of the partial removal of the external alveolar wall on the sequence of the healing process of extraction wounds was evaluated in rats.

* Departamento de Diagnostico e Cirurgia da Faculdade de Odontologia do "Campu" de Araçatuba UNESP.

** Faculdade de Odontologia de Lins 


\section{Materials and Methods}

Seventy-two male albino rats (Rattus norvegicus, albinus, Wistar), weighing 110 $120 \mathrm{~g}$ were selected and maintained on a balanced solid diet during the whole experiment, except for the first 24 hours, and they were allowed water "ad libitum".

The animals were divided into two groups of 36 each. In group I the animals had their upper right incisors extracted by means of specially adapted instruments[5]. The mucous membrane was sutured with no. 4-0 mononylon.

In group II, the mucous membrane and periosteum were incised with a no. 11 blade in the lateral-buccal region, parallel to the long axis of the upper right incisor, extending approximately the whole length of the root. After a mucoperiosteal flap was obtained, the exposed bone was partially removed from the buccal and lateral surfaces of the tooth. The osteotomy reached $1 / 3$ of the root in the apical direction and was accomplished using a chisel under manual pressure.

In the two groups surgery was performed under general anaesthesia with sodium penthobarbital and the operative field was cleansed with merthiolate dye.

Immediately after surgery all the animals received an intraperitoneal injection of Penicillin G Benzatine (16000IU).

From the two groups, 6 animals were sacrificed by sulfuric ether inhalation at $1,3,6,9,15$ and 21 postoperative days.

After sacrifice, the right maxilla was separated from the left, through an incision at the medial sagittal plane which followed the intermaxillary sutura. The specimen containing the right socket was cut out by means of straight scissors, in a cut tangent to the distal surface of the last molar.

The pieces were fixed in $10 \%$ formalin solution, decalcified in formic acidsodium citrate solution and clarified and embedded in paraffin so that the sockets could be cut in a longitudinal plane.

The blocks thus obtained were semiserially sectioned at 6 micrometer. The sections were stained with hematoxilin and eosin for histological examination.

\section{Results}

To describe the results, the dental alveolus was divided into three thirds, cervical, middle and apical, respectively, from the free gingiva to the alveolar fundus.

Twenty-four hours

In group I, the socket is filled up with a blood clot and numerous histiocytes can be seen displaying hemossiderin pigments in their cytoplasm.

On the lingual side, close to the alveolar wall, the remainder of the periodontal membrane can be seen showing good vascularization. In some instances, close to the alveolar wall, at the apical third, small numbers of osteoblasts can be seen invading the clot.

The epithelium of the gingival mucosa, with some degenerate cells, covers the connective tissue which is infiltrated by a moderate number of polymorphonuclear neutrophils.

The alveolar crest is intact on both sides. 
In group II the morphological features are not so much different from those observed in group I. However, at the level of the alveolectomy, a moderate number of polymorphonuclear neutrophils can be seen. Close to this site a few fibroblasts are evident invading the blood clot. The periodontal membrane at the middle and cervical thirds exhibits acute inflammatory infiltration (Fig. 1).

The gingival connective tissue presents intense neutrophilic infiltration and the alveolar crest, on the lingual side, remains intact.

3 days

In group $\mathrm{I}$, at the middle and apical thirds, a moderate number of fibroblasts (Fig. 2) and newly formed capillaries are observed. In some instances a few immature fibroblasts were identified close to the buccal wall.

Numerous histiocytes and some lymphocytes are found throughout the three alveolar thirds.

The alveolar crest exhibits small resorption areas. The gingival epithelium is discontinuous and the underlying connective tissue displays moderate neutrophilic infiltration.

In group II, close to the site of the alveolectomy, neutrophilic infiltration is still present; some lymphocytes and numerous histiocytes are also observed. Moderate numbers of immature fibroblasts invade the clot (Fig. 3). On the lingual side, a more evident proliferation of fibroblasts and capillaries occurs, especially at the apical third. In several places a moderate number of polymorphonuclear neutrophils and lymphocytes are observed (Fig. 4).

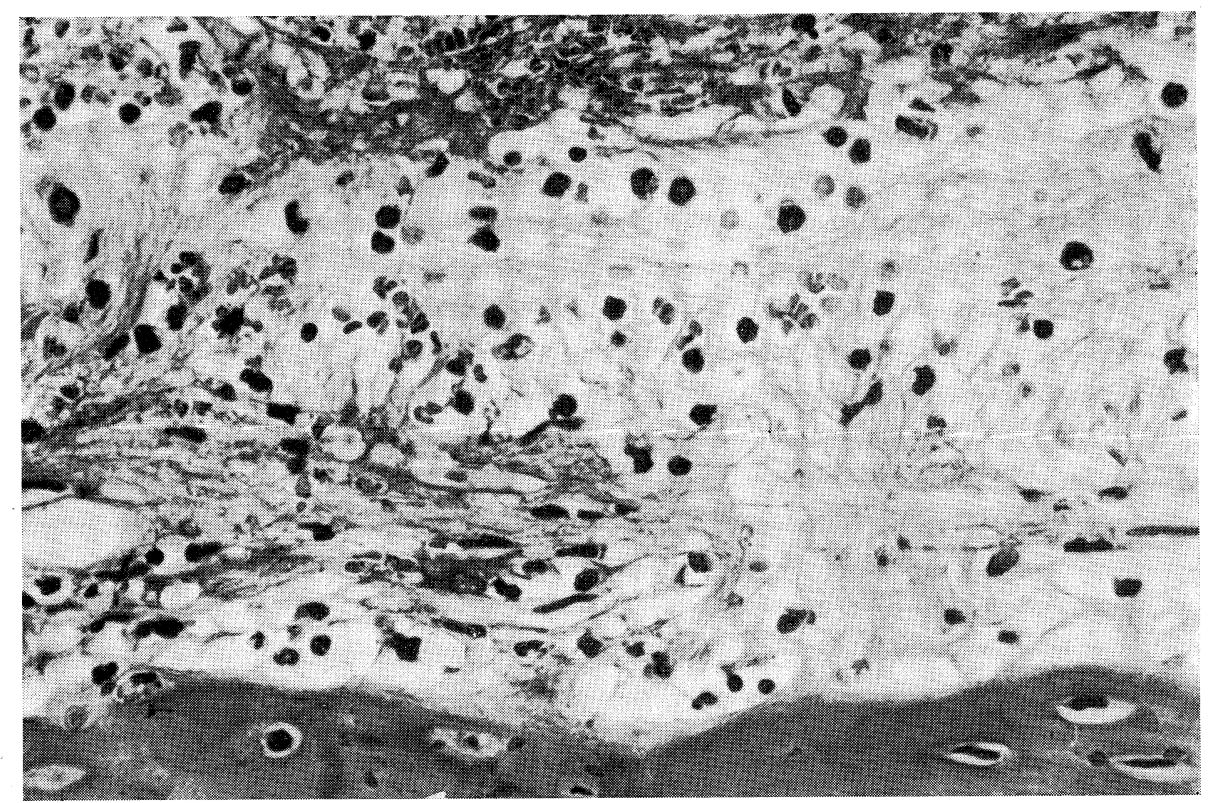

Fig. 1 Group II. Periodontal membrane at the middle third exhibits acute inflammatory infiltration. ( $24 \mathrm{hr}$, Hematoxylin and eosin stain. Original magnification $\times 126)$. 


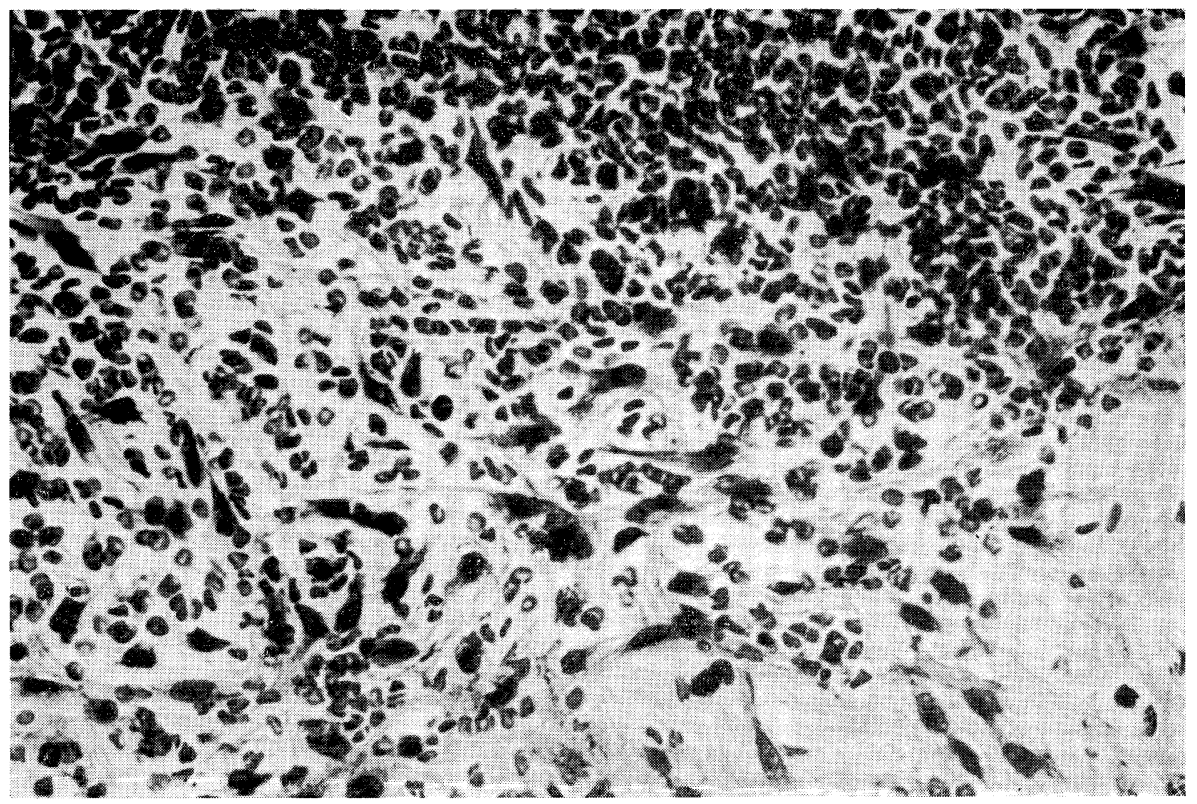

Fig. 2 Group I. Middle third of the dental socket exhibits a moderate number of fibroblasts invading the clot. (3 days Hematoxylin and eosin stain. Original magnification X 126).

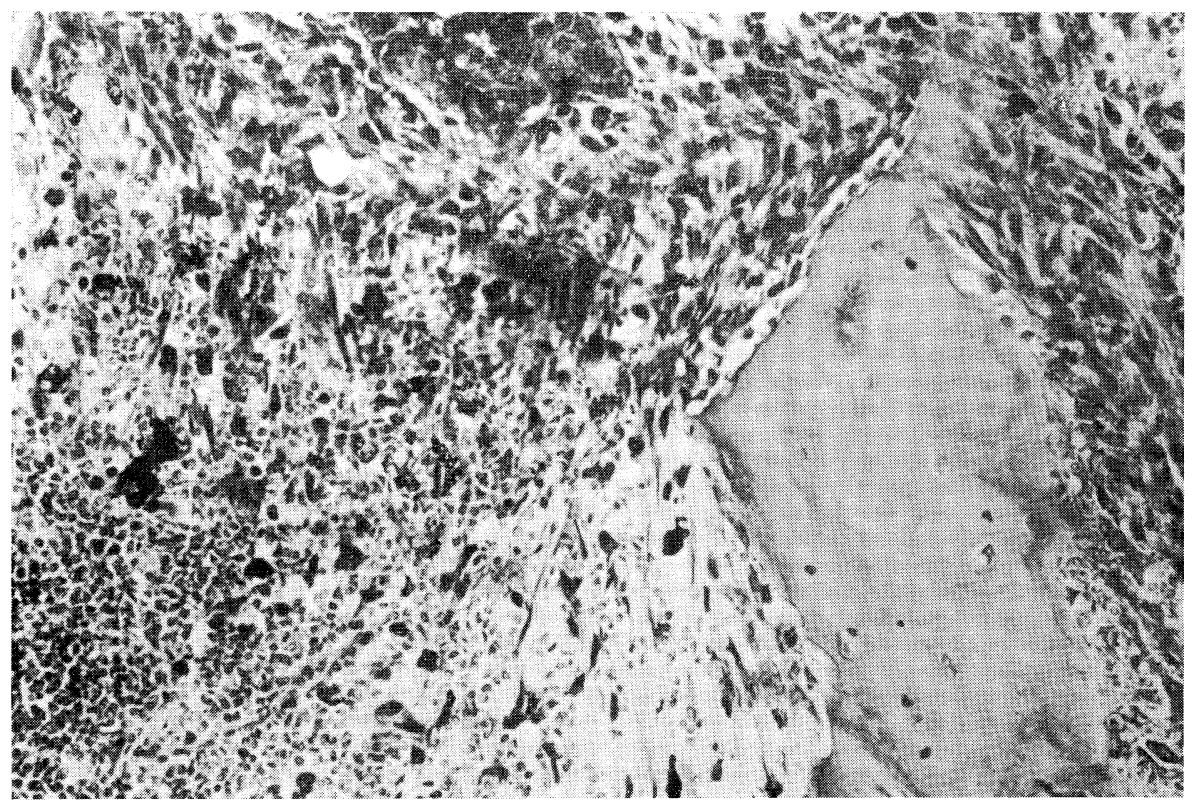

Fig. 3 Group II. Close to the site of the alveolectomy a moderate number of immature fibroblasts invade the clot. (3 days, Hematoxylin and eosin stain. Original magnification $\times 126$ ). 


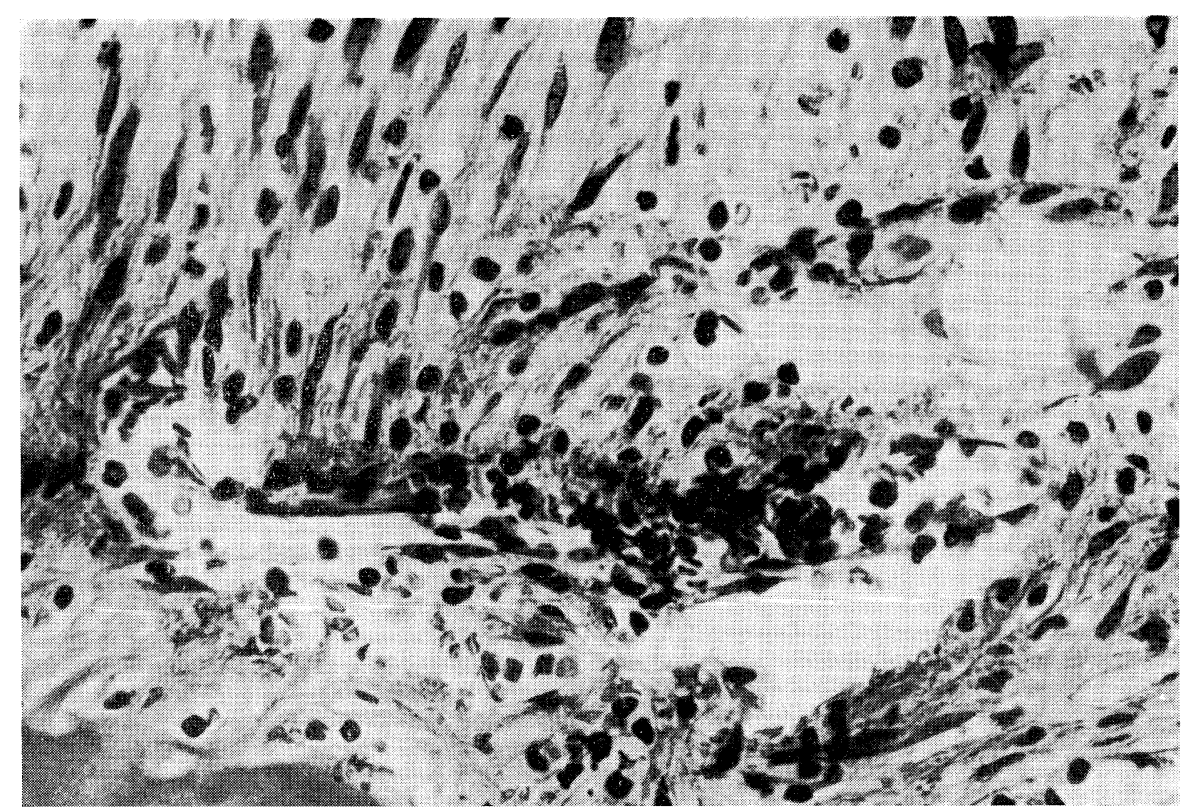

Fig. 4 Group I. Middle third of the dental socket showing a moderate number of polymorphonuclear neutrophils and lymphocytes. (3 days, Hematoxylin and eosin stain. Original magnification $\times 126$ ).

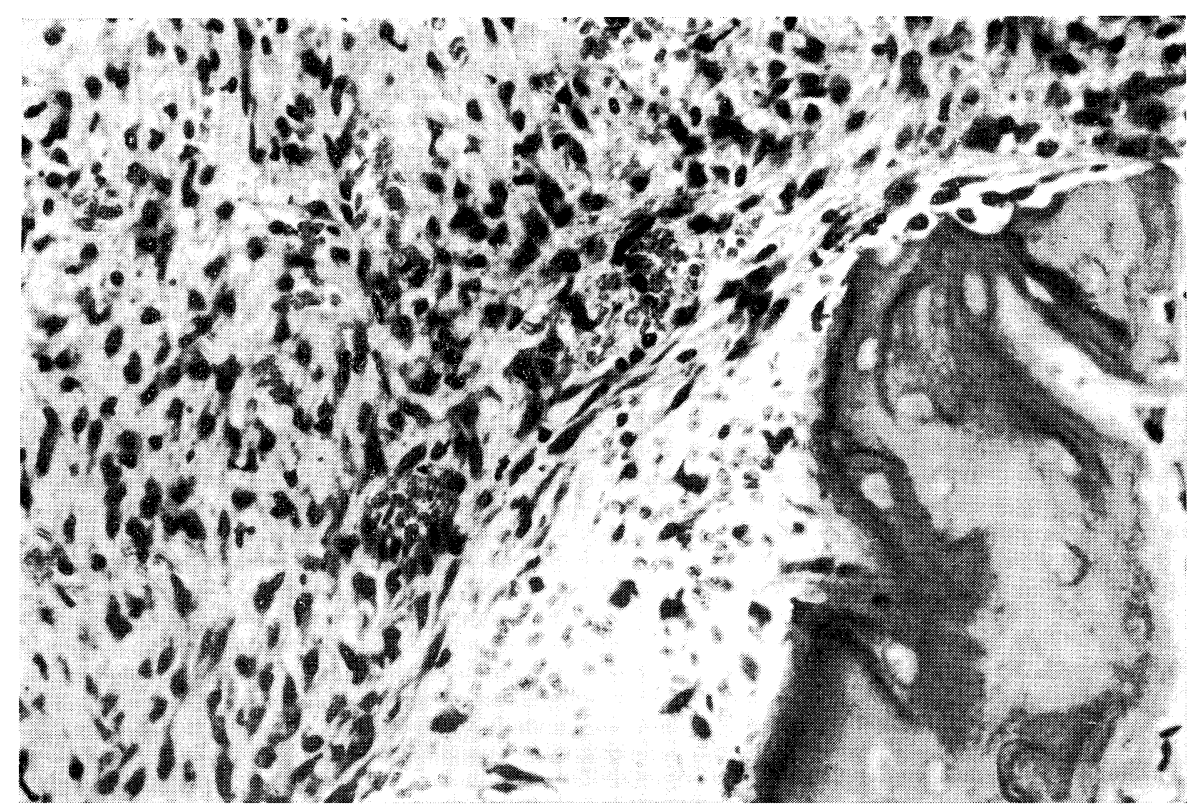

Fig. 5 Group II. Close to the site of the alveolectomy the connective tissue is rich in fibroblasts. (6 days, Hematoxylin and eosin stain. Original magnification $\times 126$ ). 
The gingival epithelium is discontinuous and the underlying connective tissue displays intense neutrophilic infiltration. The lingual alveolar crest exhibits small areas of resorption.

\section{6 days}

In group I, at the middle and apical thirds, connective tissue, rich in fibroblasts and well vascularized, is observed. In several places, however, blood clots were found exhibiting a great number of histiocytes. Sometimes, close to the fundus and alveolar wall of the middle and apical thirds, delicate newly formed bone trabeculae appeared, surrounded by numerous osteoblasts.

The cervical third, in general, is occupied by disorganized coagulum.

The gingival epithelium is still discontinuous and the underlying connective tissue displays mild inflammatory infiltration, essentially composed of lymphocytes.

The alveolar crest presents areas of resorption, especially on the lingual side.

In group II, at the apical and middle thirds, as in group I, newly formed connective tissue is observed. Close to the site of the alveolectomy, connective tissue rich in fibroblasts is formed (Fig. 5).

Nevertheless, on this same side, as the gingival margin is approached, intense inflammatory infiltration, composed of a moderate number of neutrophils or lymphocytes, is evident.

The gingival epithelium is discontinuous and the underlying connective tissue presents a moderate number of neutrophils. The lingual alveolar crest is mildly resorbed.

9 days

In group I, at the apical third, and close to the alveolar wall at the middle third, well defined bone trabeculae can be seen. With the exception of part of the middle and cervical thirds, the rest of the socket contains connective tissue which is rich in fibroblasts and blood vessels. Some newly formed trabeculae are observed within that tissue.

The gingival epithelium covers the dental alveolus, although definite characteristics are not observed. The alveolar crest exhibits areas of bone resorption and neoformation.

In group II, the morphological data at the level of the apical and middle thirds can be compared to the data collected for the last described period. At the level of the area of bone removal, however, more intense bone neoformation with more developed osseous trabeculae were observed (Fig. 6). In the remaining areas of the cervical third connective neoformation was less intense than it was at 6 days. Most of the cases showed a marked reduction in the width of the socket in the buccal lingual direction at the cervical third.

The gingival epithelium covers the socket but definite characteristics are not observed. The underlying connective tissue is infiltrated by a few lymphocytes. The alveolar crest, on the lingual side, shows areas of bone resorption and neoformation. 


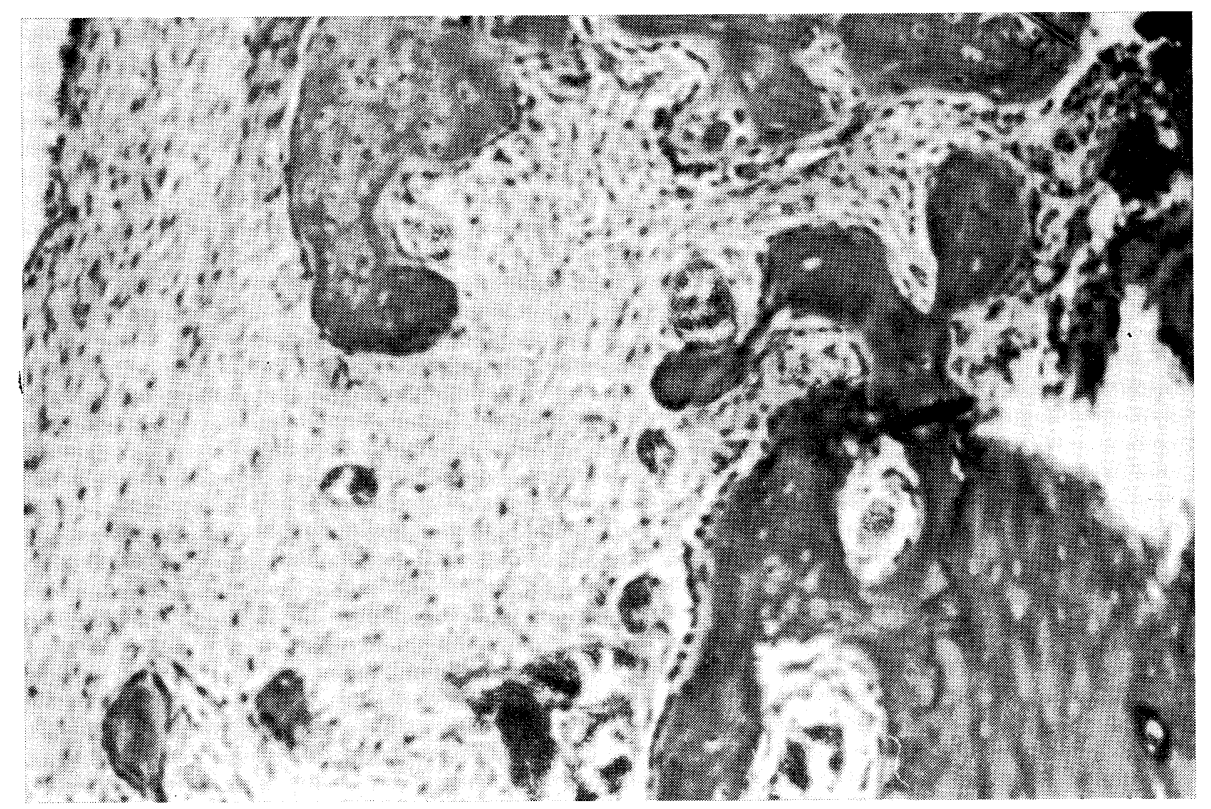

Fig. 6 Group II. Near the area of bone removal is evidence of intense bone formation. ( 9 days, Hematoxylin and eosin stain. Original magnification $\times 63$ ).

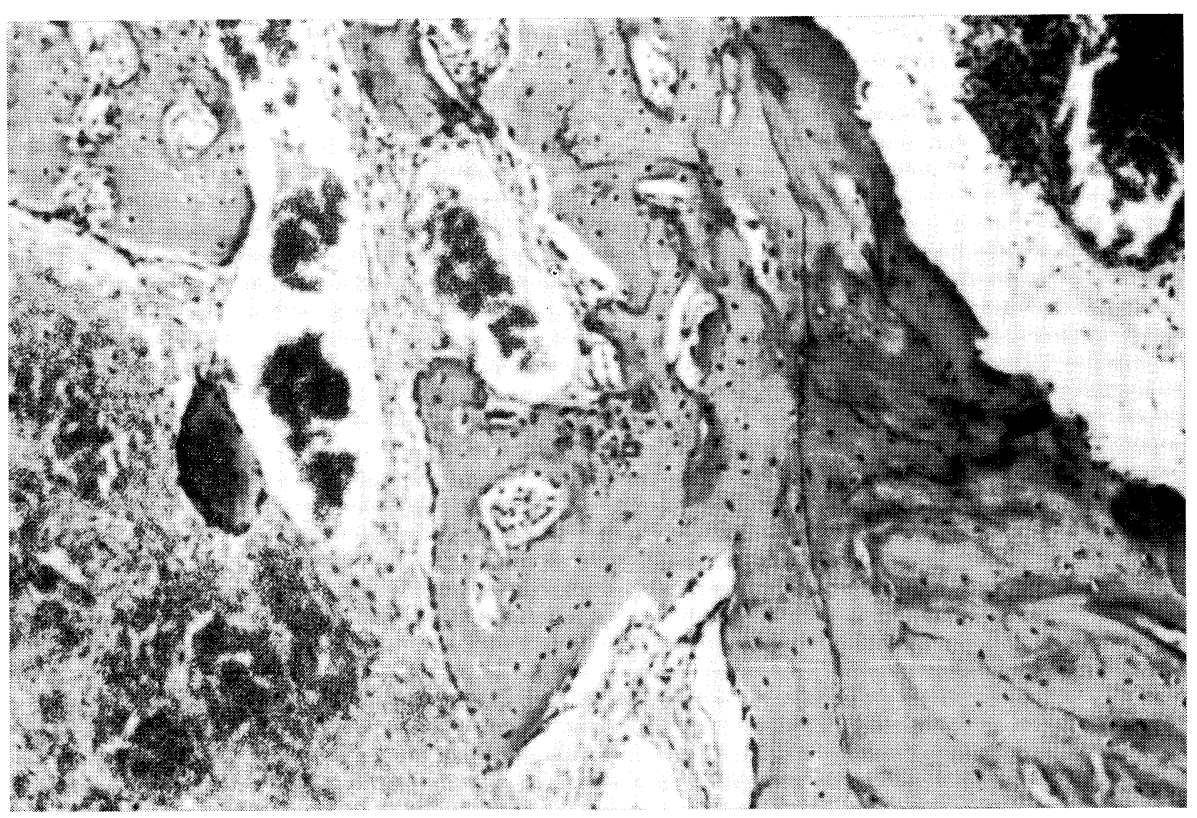

Fig. 7 Group II. The connective tissue closely rebuilt the morphology of the dental alveolus (15 days, Hematoxylin and eosin stain. Original magnification $\times 63$ ). 


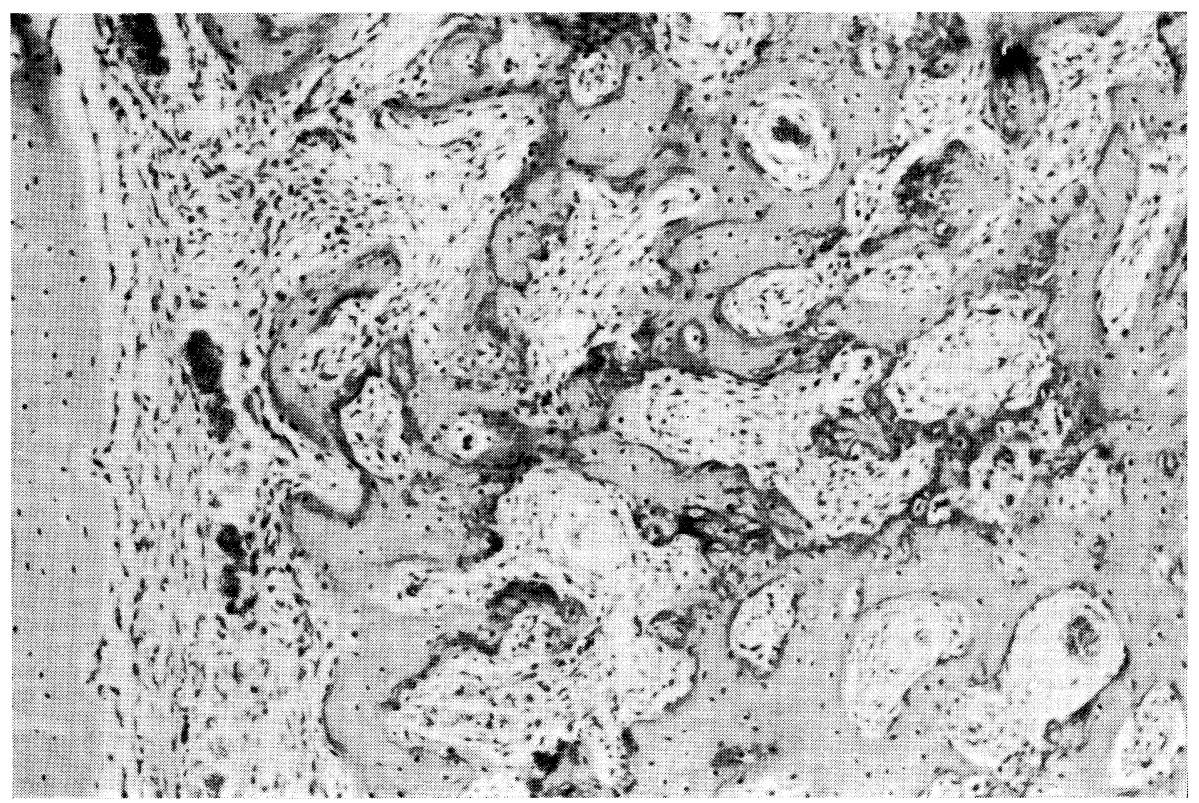

Fig. 8 Group I. Cervical third of the dental socket with signs of intense osteoblastic activity. (21 days, Hematoxylin and eosin stain. Original magnification $\times 63)$.

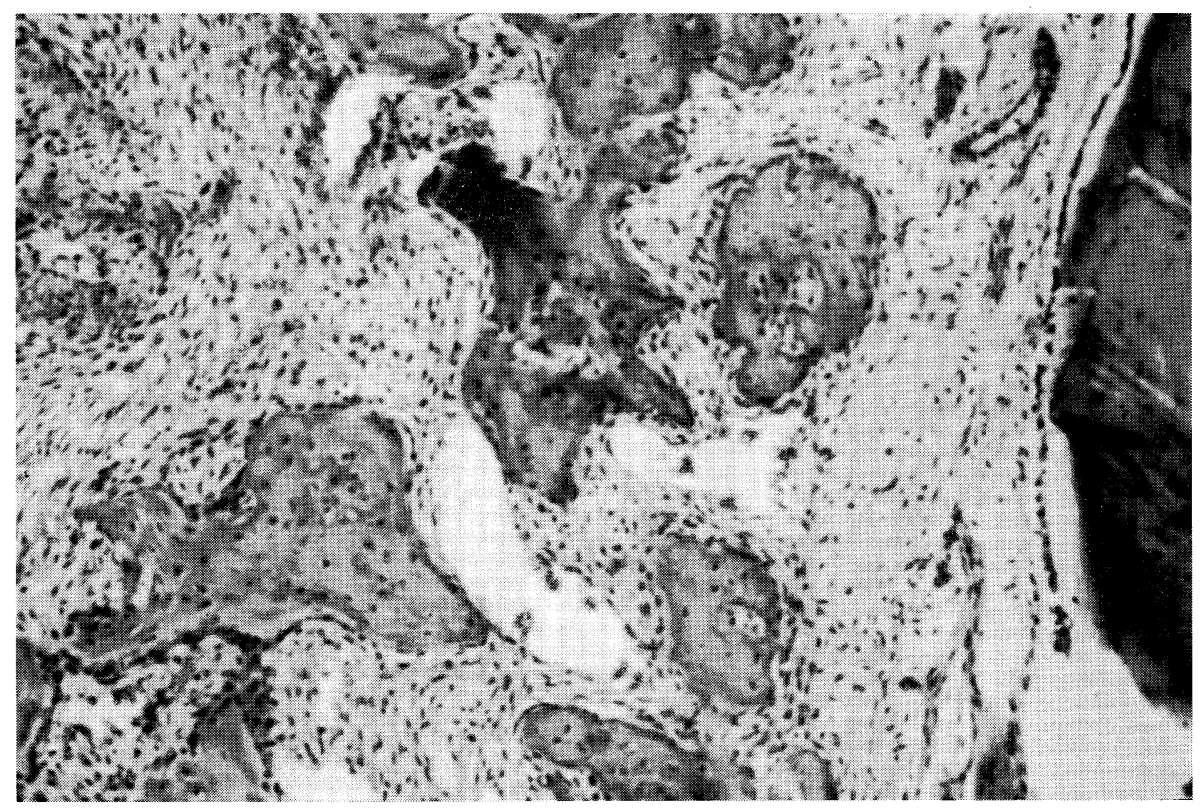

Fig. 9 Group II. Cervical third of the dental socket exhibiting poorly differentiated neoformed bone. (21 days, Hematoxylin and eosin stain. Original magnification $\times 63$ ). 
15 days

In group I, at the middle and apical thirds, the socket is filled up by thick and well defined bone trabeculae. At the cervical third they are thin and exhibit a great deal of osteoblastic activity. Occasionally, some remaining clot is found.

The alveolar crest, on both sides, displays resorption areas partially filled by newly formed bone.

In group II, the middle and apical thirds resemble the anterior group. At the cervical third, however, there are only a few scattered bone trabeculae. Proliferation of the connective tissue rebuilds, approximately, the morphology of the dental alveolus (Fig. 7), although a reduction in the labial lingual direction is evident at the cervical third.

Portions of disorganized blood coagulum are generally observed at the cervical third.

The alveolar crest on the lingual side exhibits newly formed bone over the resorbed areas.

21 days

In group I, throughout all the socket, thick and well defined bone trabeculae is seen. However, in some places there are less defined trabeculae, (Fig. 8) displaying intense osteoblastic activity at the cervical third.

The alveolar crest was remodeled on both sides.

In group II, at the apical and middle thirds, thick and well defined trabeculae are found, the same as for the areas of bone resection on the vestibular wall. In the remaining areas of the cervical third, the newly formed bone is poorly differentiated and displays thin trabeculae with intense osteoblastic activity (Fig. 9).

In all specimens, connective neoformation on the vestibular side nearly rebuilds the morphology of the dental socket. However, a decrease in the labial lingual dimension occurred at the cervial third.

The lingual alveolar crest is already remodeled.

\section{Discussion}

The extraction of an ankylosed tooth or teeth which present radicular distortions may require the use of an osteotomy and it is accomplished by partial or total removal of the buccal alveolar wall.

Although the morphological characteristics of the rat incisor sockets and the metabolism of these animals do not make them convincing models for human application, we used them because they were easily obtained and handled. Also, we could obtain a better standardization.

In the animals of group I, that is, those that were not submitted to alveolectomy, the healing process presented morphological characteristics comparable to those described elsewhere[3,5].

So, in the last experimental period the socket was filled up by well defined bone trabeculae. The presence of poorly defined bone in some sites of the cervical third, as observed in this paper, has also been noted in other studies in which one of the experimental groups was similar to ours $1,6,7$. 
On the other hand, the healing process of the extraction wound after the partial removal of the vestibular wall was comparable to that described for group I. At the cervical third, however, we observed a variation in the "normal" pattern of healing.

The inflammatory infiltrates, present in the initial periods on the vestibular side of the cervical third or at the level of the periodontal membrane, are probably due to the more intense trauma promoted by removal of the vestibular wall.

This is corroborated by the clinical observations of ScHUCHARDT[10], who observed that mechanical irritation after dental extraction elicits an inflammatory reaction which, according to its intensity, may cause alterations in the blood clot.

Simpson[13] described a great number of inflammatory cells between the flap and bone after an osteotomy.

Besides that, the method employed for osteotomies may alter the healing process[11,12]. The author compared the results obtained after alveolectomies using chisels and burs. He concluded that the use of chisels is less harmful to healing because bone fragments are more easily removed than those consequent to the use of burs.

The maintenance of the inflammatory phase in group II delayed fibroblast and capillary proliferation. This fact may have determined the delay in the chronology of the healing process, verified in the sockets where the vestibular wall was partially removed. Although, close to the borders of that wall, connective neoformation was faster and more intense.

SCHRAN[9], based on a study in dogs, concluded that healing after an alveolectomy is faster because the alveolar area becomes smaller when the vestibular wall is removed.

It is probable that this is true because when practically the whole vestibular wall is removed it causes a drastic decrease in the area to be repaired.

In our work, besides the characteristic morphology of the alveolus of rat incisors, the alveolar wall was only partially removed which reduced the area to be repaired to only the level of the cervical third.

Contributing to this delay, another morphological aspect, observed in the experimental group is, doubtless, the area submitted to alveolectomy, as stated before. As a consequence, bone differentiation appeared earlier, although restricted to the border of the removed osseous wall. This is related to the surgical procedure.

So, after an osteotomy and dental extraction, the flap is sutured in position, promoting contact of the periosteum with the blood clot. It is very probable that the immature fibroblasts observed close to the area of the alveolectomy, came from the periosteum, at least some of them.

The role of the periosteum in the healing process of extraction wounds has been discussed by several authors for a long time[9].

Nowadays, however, the periosteum is considered to play an important role in bone repair. In the presence of fractures, for example, the periosteum close to the severed area undergoes intense fibroblast proliferation which produces granulation tissue rich in cellular elements.

One observation which enhances the role of the periosteum in the proliferation of fibroblasts at the level of the alveolectomy is: at the vestibular side of the teeth 
with continued growth, we found, between the enamel and bone, a thin layer of connective tissue which is principally responsible for nutrition of the ameloblasts. This connective tissue is generally eliminated when these teeth are extracted. This can be proved by histological sectioning of the sockets 24 hours postoperatively.

The almost total absence of this tissue elicits, on the control sockets, less intense connective tissue neoformation on the vestibular side, when compared to the lingual side, where great quantities of periodontal membrane remained attached to the bone[2,5].

Another important feature, observed in this study, refers to the alveolar wall. It is clear that, due to the alveolectomy, a loss of the morphology of the alveolar process occurs[8,9].

Besides the loss of width at the cervical third, in the labial lingual direction, we also noted a loss in height on the vestibular side.

According to Ries-Centeno[6], anterior dental extractions by alveolectomy promote an exaggerated resorption of the alveolar ridge and suggest that prior careful planning, based on clinical evaluation and X-ray examination, should be done if an alveolectomy is indicated.

In our work, although the sockets lost their morphology, we did not observe any intense resorption on the remaining bone wall.

Finally, we would like to point out, again, that our results should not be totally extrapolated to clinical use, specially if you consider that, in human teeth, part of the periodontal membrane remains attached to the whole estension of the alveolar wall which is not the case in rats. Nevertheless, several of the biological aspects observed enhance the view that the extraction of teeth, by means of an alveolectomy, should only be elected when other techniques can not be employed[10] and with very careful clinical examination and radiographical support.

\section{Summary and Conclusions}

Seventy-two male albino rats were used. Their upper right incisors were extracted with forceps through the alveolar route or after elevation of a mucoperiosteal flap and partial removal of the buccal bony plate; the wounds were sutured. The animals were sacrificed after 1, 3, 6, 9, 15 and 21 days. The pieces of jaw containing the dental alveoli were processed for routine histological analysis. Semi-serial sections stained with hematoxylin and eosin showed that the removal of the buccal bony plate was related to: (1) a more intense and prolonged inflammatory reaction within the socket, (2) a delayed chronological evolution of its healing process, (3) early connective tissue neoformation near the edges of the sectioned bony tissue, and (4) a shape loss of the alveolar crest at the cervical third.

\section{Acknowledgment}

Work supported by Fundação de Amparo à Pesquisa do Estado de São Paulo (FAPESP) (Proc. 79/0878). 


\section{References}

[1] Brosch, F. 1962. Extracción dentaria operatória. In: Schuchardt, K., Tratado general de odonto-estomatologia. Madrid, Alhambra. tomo 3, v. 1, p. 371-2.

[2] Carvalho, P. S. P., Okamoto, T. and Carvalho, A. C. P. 1982. The influence of intra-alveolar curettage on wound healing after tooth extraction. A histological study in rats, J. Nihon Univ. Sch. Dent., 24(1), 28-34.

[3] Haddad, A., Hetem, S., Brandãd, H. J. and Santos-Pinto, R. 1965. A tetraciclina no processo de reparo de feridas de extração dental em ratos, Rev. Fac. Odont. Araçatuba, 1(2), 23-32.

[4] Magalhães, A. E. O., OKamoto, T. and Barroso, J. S. 1982. Influência da fratura da crista óssea alveolar no processo de reparo em feridas de extração dental. Estudo histológico em ratos, Rev. Ass. paul. cirurg. Dent., 36(2), 203-213.

[5] Окамото, T. and Russo, M. C. 1973. Wound healing following tooth extraction, histochemical study in rats, Rev. Fac. Odont. Araçatuba, 2(2), 153-169.

[6] Ries-Centeno, G. A. 1975. Cirurgia bucal. 7 a ed. Buenos Aires, El Ateneo.

[7] Salomão, J. I. S., Grandini, S. A. and Okamoto, T. 1974. Processo de reparo em feridas de extração dental em ratas ooforectomizadas. Estudo histológico, Rev. Fac. Odont. Araçatuba, 3(2), 183-195.

[8] Sanches, M. C. 1980. Implante de silicone em alvéolos dentais. Estudo histológico em ratos. Araçatuba, Faculdade de Odontologia de Araçatuba-UNESP. /Dissertação de Mestrado/.

[9] SAntos, P. V. Jr. 1980. Implante de "Proplast" em alvéolo dental spós exodontia por alveolectomia total. Estudo histológico em cães. Araçatuba, Faculdade de Odontologia de Araçatuba-UNESP. /Dissertação de Mestrado/.

[10] Schran, W. R. 1929. A histologic study of repair in the maxillary bones following surgery. J. Amer. dent. Ass., 16, 1987--97.

[11] Simpson, H. E. 1961a. Healing of surgical extraction wounds in macacus rhesus monkeys. II. The effect of chisels, J. oral Surg. Anesth. Hosp. dent. Serv., 19, 4-9.

[12] Simpson, H. E. 1961b. Healing of surgical extraction wounds in macacus rhesus monkeys. I. The effect of burns, J. oral Surg. Anesth. Hosp. dent. Serv., 19, 127-9.

[13] Simpson, H. E. 1969. The healing of extraction wounds, Brit. dent. J., 126(12), 550-7. 